\title{
Notas sobre a Teoria da Arte na fotografia de Jeff Wall e Thomas Struth
}

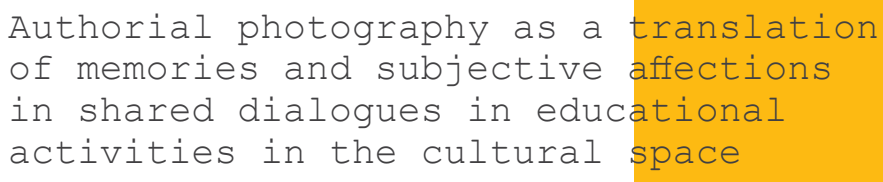

José Carlos Pereira

1 Professor auxiliar na Faculdade de Belas-artes da Universidade de Lisboa. E-mail: j.dosreis@belasartes.ulisboa.pt 


\section{Introdução}

Integrados respectivamente na Escola de Vancouver, e na Escola de Düsseldorf, Jeff Wall e Thomas Struth manifestam no seu trabalho fotográfico um pensamento que confirma a autonomia da fotografia, re-questionando a noção de reprodutibilidade mecânica que constituiu um dos seus marcos estético-ideológicos. A proximidade do primeiro à artes plásticas, principalmente à pintura, mas também ao cinema, e a abordagem historiográfica de Struth, presente na reconceptualização da tipologia do retrato, ou na revisão do estatuto da imagem e do espectador, possibilitam pensar a fotografia a partir do movimento da própria história em sentido hegeliano, o que faz aparecer, no trabalho de Wall, a própria "gestualidade" como tradução plástica (no caso, fotográfica) de um conjunto de acções que ganham sentido no âmbito de uma gramática convencionada de signos, de que o corpo é o veículo privilegiado de expressão; no trabalho de Struth, o espaço surge como tradução dramatúrgica e metafórica da história, e consequentemente da identidade das sociedades, reveladas pela imagens, contrariando ambos os fotógrafos a morte da arte vaticinada por Hegel, a partir do descrédito a que o próprio filósofo a votou enquanto encarnação sensível da ideia.

Jeff Wall estudou inicialmente história de arte e estética, e cedo se demarcou do conceptualismo, enveredando por uma fotografia que recupera da pintura a ideia de quadro (tableau), que potencia através do grande formato e da retroiluminação, por via da luz colocada atrás de um pano branco sobre o qual instala a fotografia, dispositivo que, à semelhança de um plinto, não deixa de estabelecer, simultaneamente, uma relação com a escultura, potenciando também a sua dimensão monumental. Esta ideia, como confessou, surgiu-lhe da observação dos grandes painéis de publicidade existentes nos aeroportos e em vários locais das cidades, nos quais a imagem parece flutuar, dada uma certa transparência que lhe é concedida pela luz branca.

Por seu turno, Struth ultrapassa uma aparente ideia da espacialidade formal, e consequentemente de paisagem, por uma dupla via: por um lado, mantém presente a lição que recebeu, na academia de Düsseldorf, dos seus mestres Bernd e Hilla Becher; estes artistas evitavam a linha de horizonte nas suas fotografias, eliminando a possibilidade de serem lidas como paisagem, aproximando-as da escultura, por via da monumentalização das estruturas que captavam, inserindo-se, simultaneamente, o seu trabalho numa dimensão de arquivo; por outro lado, Struth invoca o conceito de "local de crime", proposto por Walter Benjamin, a propósito das fotografias de Eugène Atget. ${ }^{1}$

\section{Jeff Wall}

O conceito de "quadro fotográfico", que JeffWall progressivamente desenvolveu a partir de Storyteller, de 1986 (Fig. 1), concilia três possibilidades, a saber: a 
reconceptualização da paisagem em termos fotográficos, utilizando-a como cenário da performance dos actores que dirige; a renovação da fotografia de rua (street photography), por via da encenação, como acontece em Mimic (Fig.2); finalmente, a dimensão documental como denominador comum das duas possibilidades anteriores, dimensão essa que recupera a escala da representação do corpo humano na pintura de história.

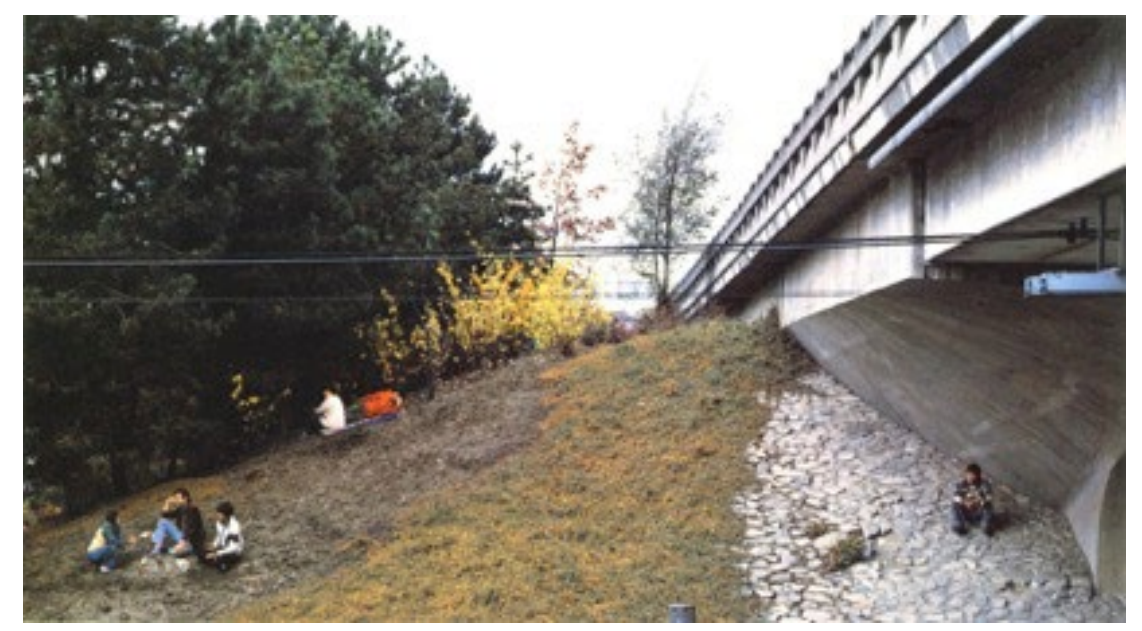

Fig. 1: The Storyteller, 1986. Transparência emcaixa de luz. Dim: $229 \times 437$ cmVischer, T. \& Naef, H. (Eds.). (2005). Jeff Wall: Catalogue Raisonné 1978-2004. Basel: Schaulager Steidl

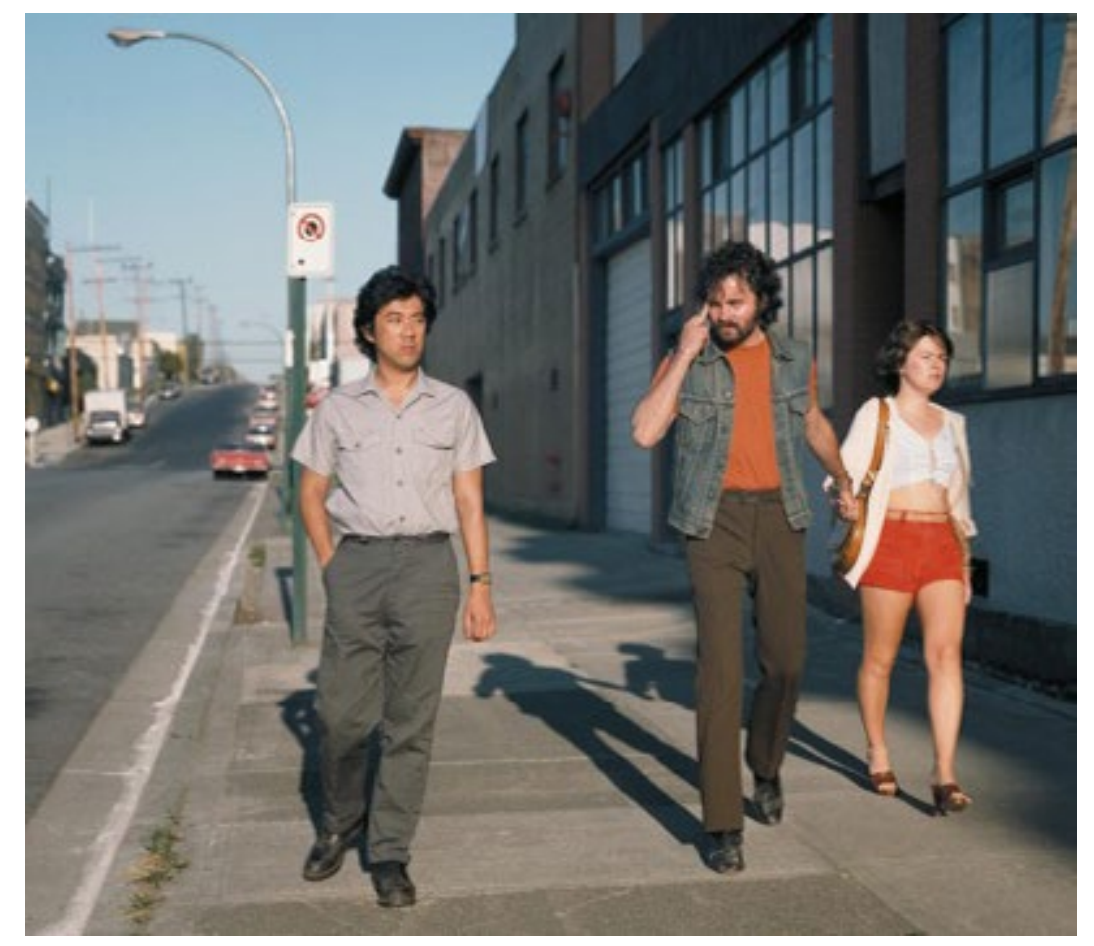

Fig. 2: Mimic, 1982 Transparência em caixa de luz. Dim: 198 × 228,5 cm. Vischer, T. \& Naef, H. (Eds.). (2005). Jeff Wall: Catalogue Raisonné 1978-2004. Basel: Schaulager Steidl

Em oposição a uma certa instantaneidade da fotografia, que caracteriza, por exemplo, o trabalho de Robert Frank, Wall reconheceu, através da composição 
encenada, que era possível conceder um caráter monumental à fotografia de rua ${ }^{2}$, contrariando a doutrinação de Greenberg, que defende a especificidade do medium como garantia da autonomia da arte. Simultaneamente, a rejeição desta doutrina estende-se à relação da sua fotografia com a literatura, particularmente com Mishima e Kafka, como no caso de Odradek, Táboritská 8, Praga (Fig. 3), tomando-a como ponto de partida para conceber e encenar, com actores profissionais, as suas imagens, mantendo uma relação igualmente próxima com o cinema.

Como o próprio reconhece, na relação histórica com o teatro, o cinema permite a criação de uma "esfera de intimidade fotográfica e pictórica" 3 , esfera que a fotografia também produz através do trabalho com os actores, enquanto mediação entre o fotógrafo e a construção da personagem. Se o movimento perceptível nas suas imagens advém da própria caixa de luz, do cinema recolhe uma outra influência, como é visível na série Partial Account (Fig. 4), na qual subverte a sequência e o movimento dos fotogramas, criando espaços "neutros" entre eles, subvertendo agora também a própria dimensão narrativa.

Breughel, entre outros, não só reitera a ideia da representação no seu trabalho, como supera as tentativas desconstrucionistas desta prática, vigentes na década de 1970, e integra-se ainda na reavaliação que o fotógrafo faz do legado das vanguardas, confirmando o processo de figuração como um dos princípios básicos da fotografia.

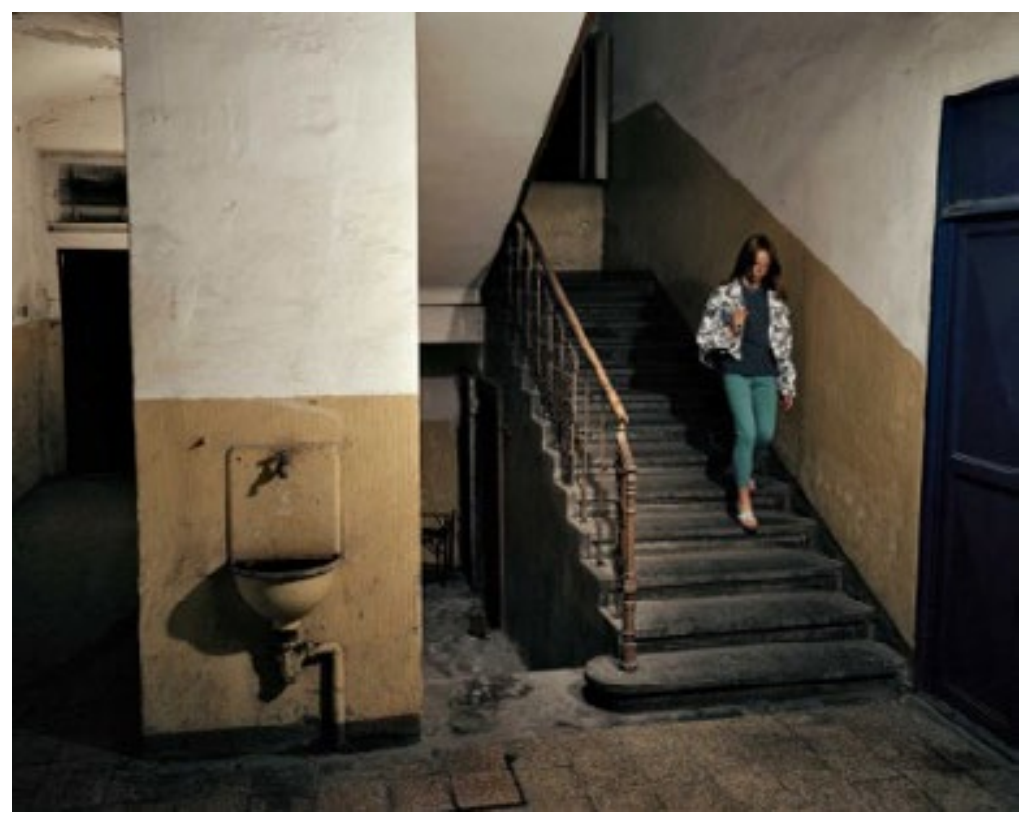

Fig. 3: Odradek, Táboritská 8, Praga, 1994. Transparência em caixa de luz. Dim: 229 x 289 cm. Vischer, T. \&amp; Naef, H. (Eds.). (2005). Jeff Wall: Catalogue Raisonné 1978-2004. Basel: Schaulager Steidl 


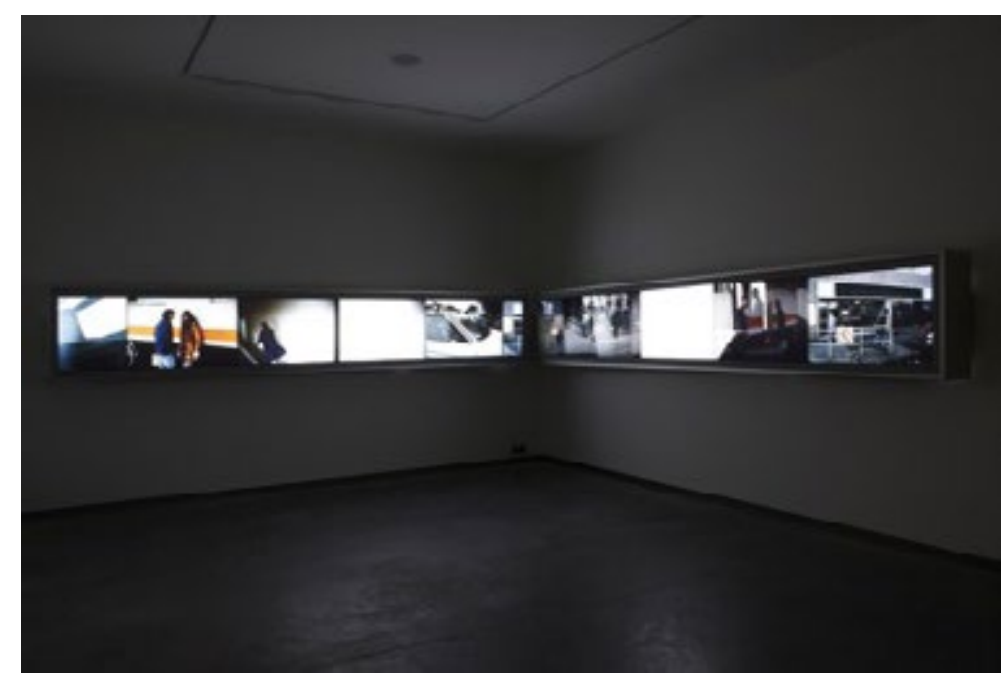

Fig. 4: A Partial Account, 1997. Transparências em caixas de luz. Dim: 56 × 402,4 cm. Helga de Alvear Collection, Madrid.

A aproximação à pintura de Delacroix, como assume em The Destroyed Room (Fig. 5), realizada a partir de A Morte de Sardanápalo, mas igualmente à de Manet, como acontece em Picture for Women (Fig. 6) ou Insomnia (Fig. 7), à de Seurat, ou Breughel, entre outros, não só reitera a ideia da representação no seu trabalho, como supera as tentativas desconstrucionistas desta prática, vigentes na década de 1970, e integra-se ainda na reavaliação que o fotógrafo faz do legado das vanguardas, confirmando o processo de figuração como um dos princípios básicos da fotografia.

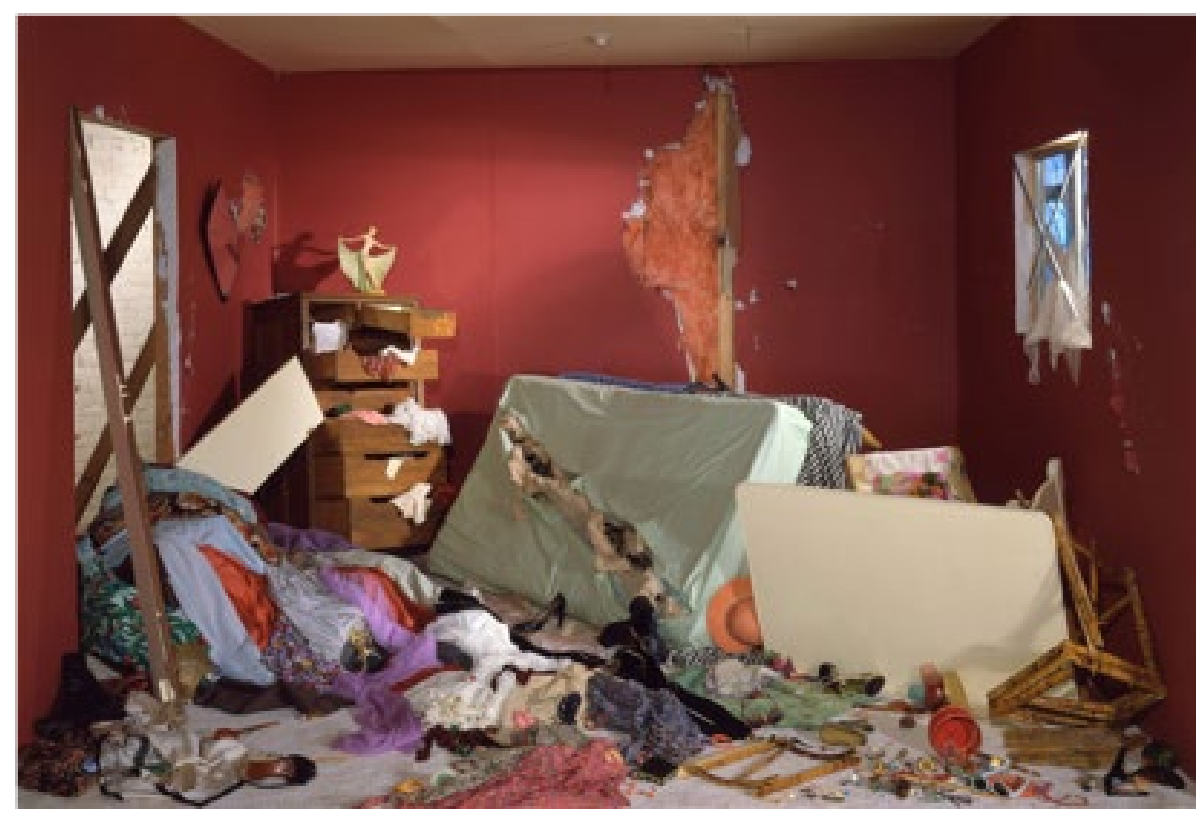

Fig. 5: The Destroyed room, 1978. Transparência em caixa de luz Dim: 159x234 cm. 


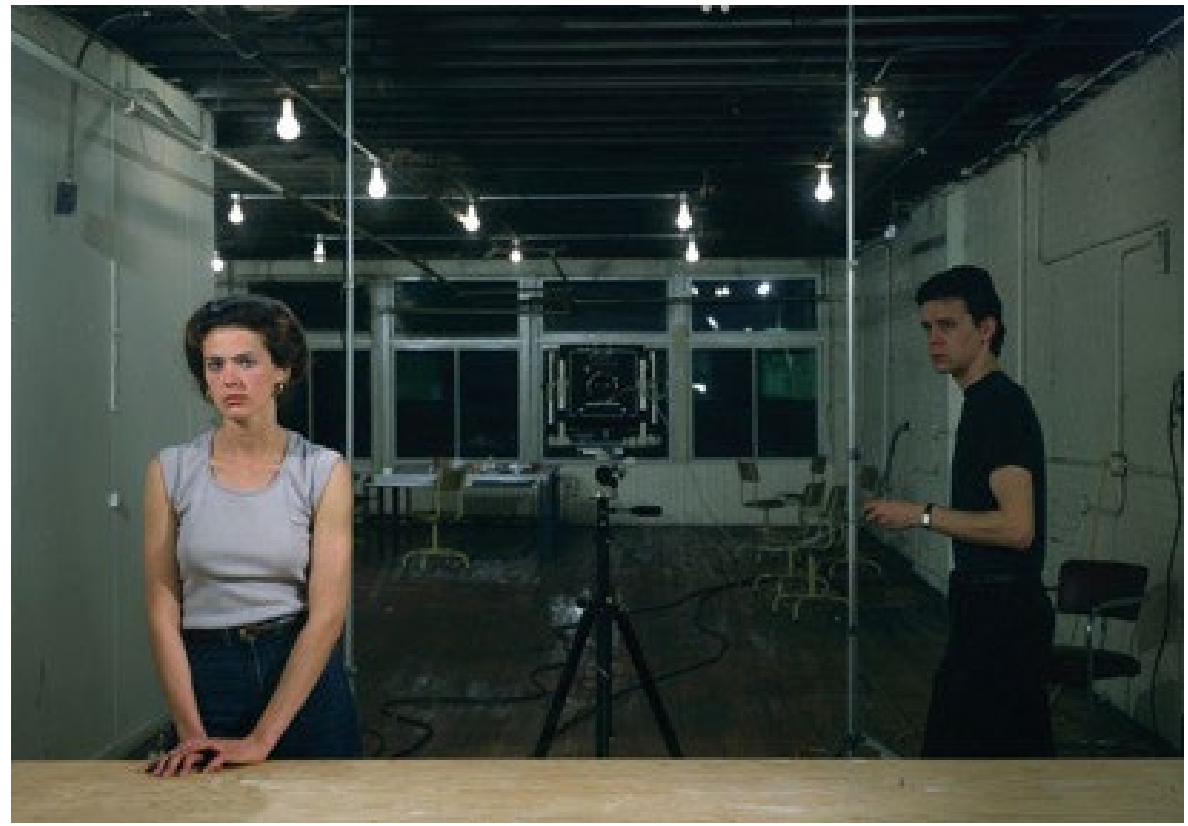

Fig. 6: Picture for woman, 1979. Transparência em caixa de luz Dim: $142.5 \times 204.5 \mathrm{~cm}$. Vischer, T. \&amp; Naef, H. (Eds.). (2005). Jeff Wall: Catalogue Raisonné 1978-2004. Basel: Schaulager Steidl.

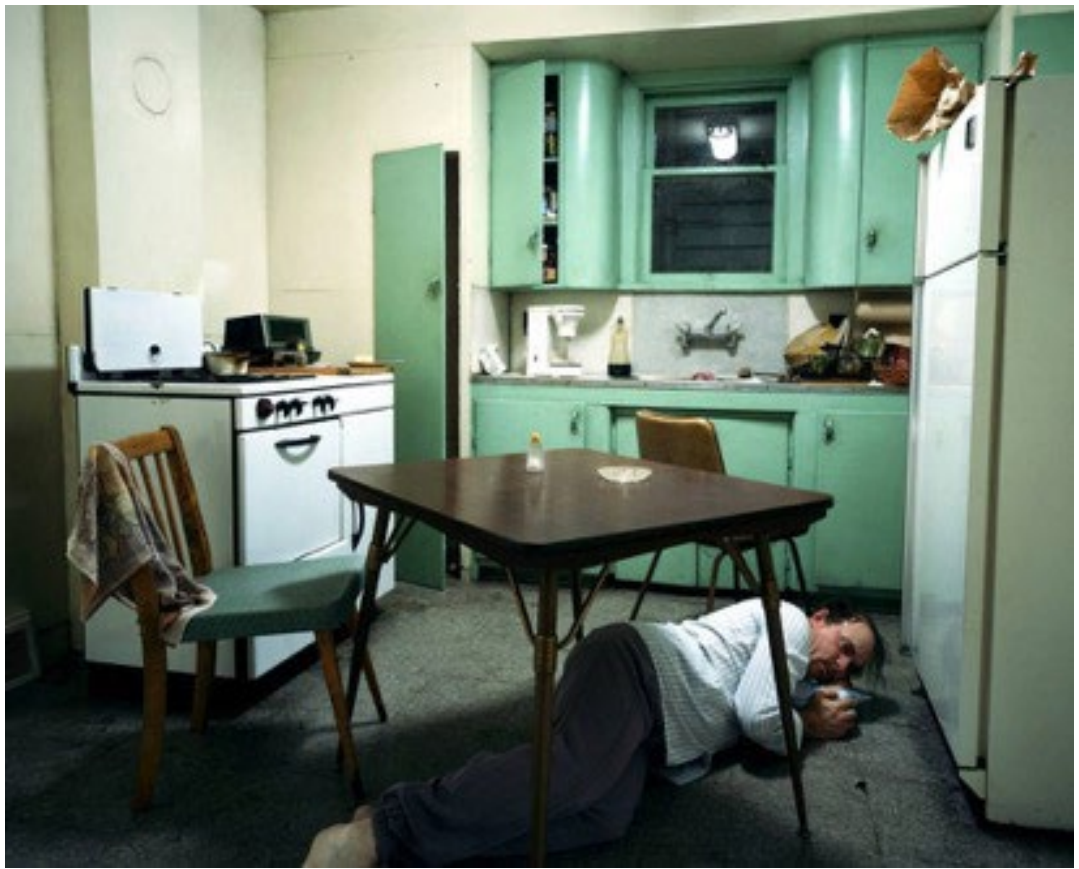

Fig. 7: Insomnia, 1994. Transparência em caixa de luz. Dim: 167 x 237 cm. Vischer, T. \& Naef, H. (Eds.). (2005). Jeff Wall: Catalogue Raisonné 1978-2004. Basel: Schaulager Steidl.

Porém, se a leitura da história da arte leva Wall a rejeitar a feição dialéctica que caracterizou algumas vanguardas, a qual, previsivelmente, levaria à abstracção como 
o culminar da autonomia da arte no século XX, o seu trabalho não deixa de importar metodologias criadas no seio do modernismo, como o corte e a assemblage, que consegue, ora manualmente, através do corte e colagem dos negativos, ora através da manipulação digital, e do processo da fotomontagem, que utiliza a partir do início da década de 1990. Se o processo de montagem é usado para quebrar a unidade tradicional do espaço, Wall utiliza-o justamente para apagar as costuras da ligação dos vários fragmentos da imagem, criando, assim, uma nova "ilusão" da unidade desse mesmo espaço tradicional; simultaneamente, e, como afirma, este processo permiteIhe, à semelhança da pintura, deter-se em determinados elementos, e, ao mesmo tempo, superar a pintura, pois na fotografia há a coexistência de vários momentos temporais, o que acaba por fragmentar a própria perspectiva, precisamente através da técnica da assemblage.

Se a perspectiva caracteriza a pintura desde o renascimento, a "representação fragmentada" dos elementos do quadro, que Wall observou em Manet, permiteIhe uma reconfiguração, na fotografia, da própria ideia da unidade da pintura ${ }^{4}$. Por outro lado, o corte concede à fotografia uma marca de "manufactura", e subtrai-a a qualquer ilusionismo de perfeição, isto é, a obra exibe as marcas do seu próprio processo plástico, o que se concilia com o caráter narrativo e figurativo, que o fotógrafo considera indissociáveis da prática fotográfica.

Por outro lado, a reflexão teórica de Jeff Wall recolhe da filosofia o contributo para a constituição de uma nova ontologia da imagem fotográfica, a mesma que confirma nos seus ensaios, e que estrutura as suas fotografias. $O$ conceito nietzschiano de verdade, enquanto dispositivo social, desligado de qualquer dimensão metafísica ou teleológica, e que se manifesta em diversas perspectivas, é agora reivindicado pelo fotógrafo para produzir o distanciamento em relação às suas personagens, ou seja, as personagens que cria, por via da dramaturgia inerente ao seu processo de trabalho, parecem manifestar os seus próprios pontos de vista, granjeando, deste modo, a sua autonomia.

O conceito de grotesco ancora igualmente a estética da sua fotografia, e operase por via da convivência entre o que aquilo que o fotógrafo chama de pessoas "reais" e de fantasmas", ou "espectros", e no qual a própria noção de ficção, que emoldura as suas imagens, se articula em profundidade com esse mundo em que a verdade, como afirmou Nietzsche, é "um exército móvel de metáforas, de metonímias, de antropomorfismos" ${ }^{5}$, como acontece em Dead Troops Talking (fig. 8), em que há um núcleo de três personagens que, no meio do cenário de guerra, parecem insolitamente fazer um jogo entre eles, ou em The Vampire's Picnic (fig. 9), sem prejuízo da crítica ideológico-política, que ambas não pretendem esconder, e se encontra subjacente a todo o trabalho de Jeff Wall.

4 lbid., p. 55.

5 Nietzsche, Friedrich, O Nascimento da Tragédia (Acerca da Verdade e da Mentira no Sentido Extramoral), Relógio D’Água, Lisboa, 1997, p. 221. 


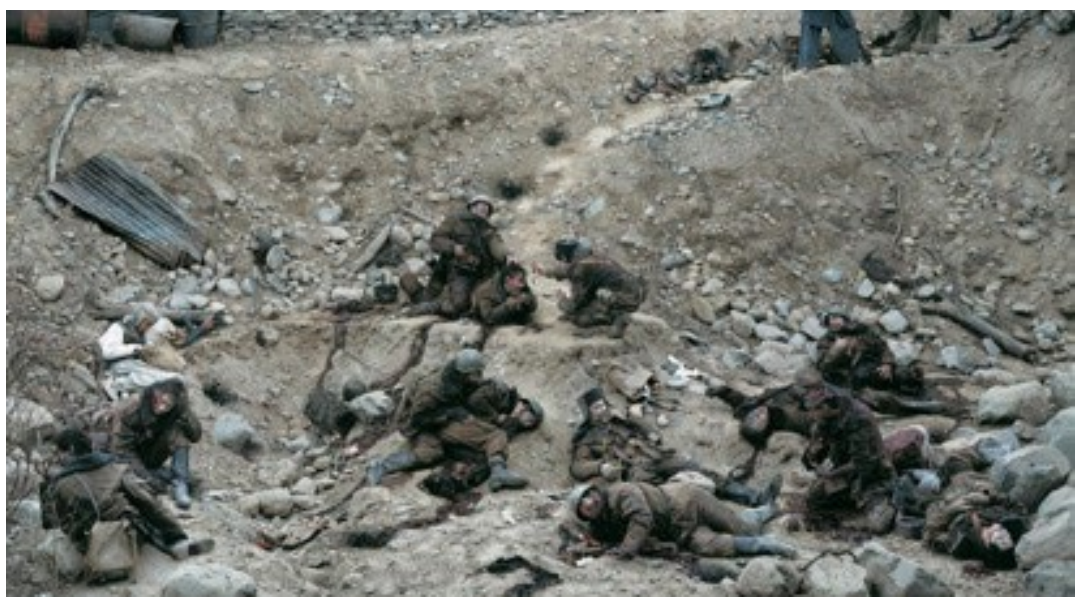

Fig. 8: Dead Troops Talk (a vision after an ambush of a Red Army Patrol, near Mogor, Afghanistan, winter 1986), 1992. Transparência em caixa de luz. Dim: 229 x 417 cm. Vischer, T. \& Naef, H. (Eds.).

(2005). Jeff Wall: Catalogue Raisonné 1978-2004. Basel: Schaulager Steidl

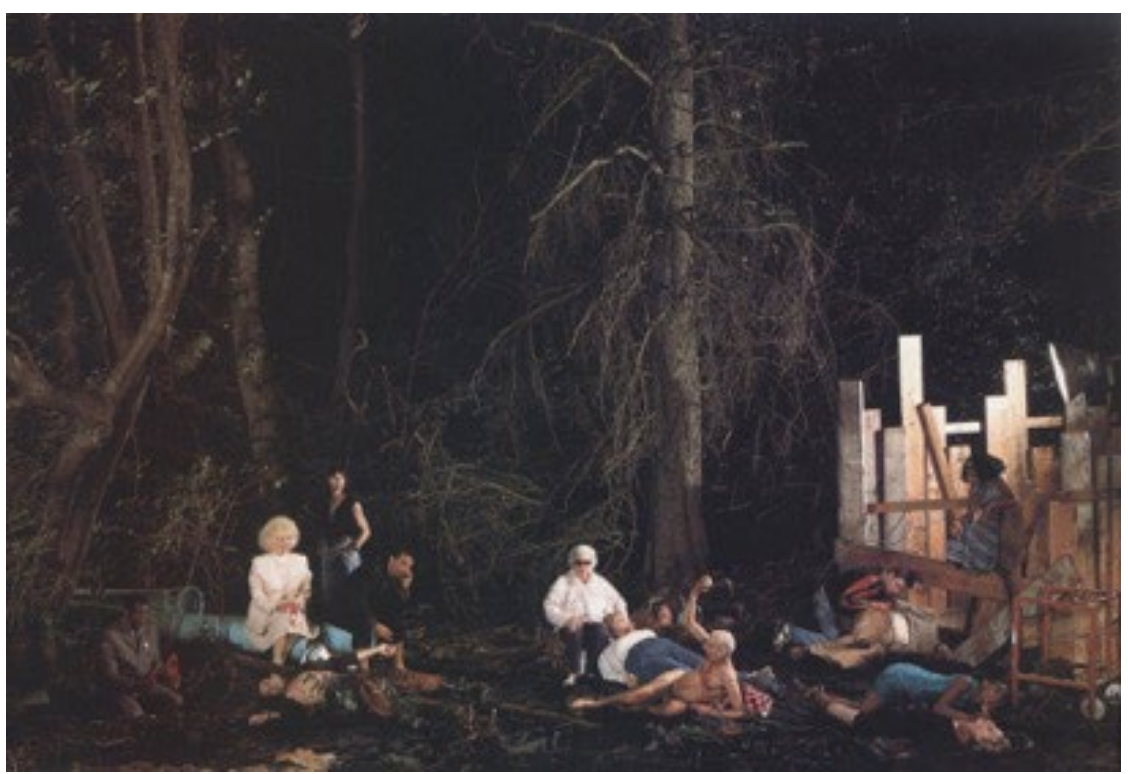

Fig. 9: The Vampire's Picnic, 1991. Transparência em caixa de luz. Dim: 229 x $335 \mathrm{~cm}$. Vischer, T. \& Naef, H. (Eds.). (2005). Jeff Wall: Catalogue Raisonné 1978-2004. Basel: Schaulager Steidl.

\section{Thomas Struth}

A fotografia de Thomas Struth parte do conceito de história, cujo movimento se manifesta no modo como o urbanismo e a arquitectura das cidades reflectem as vivências dos seus habitantes ao longo do tempo. Tomando como referência inicial do seu trabalho as fotografias que realizou em Roma e Nápoles, é possível constatar dois modos de fazer cidade, no caso de Roma (Fig. 10), através de uma prática projectual erudita, que envolveu renomados arquitectos e urbanistas, no caso de Nápoles (Fig. 11), e em profundo contraste com a cidade eterna, o espaço urbano espelha inequivocamente uma via diferente, com forte cunho popular na criação de 
cidade, na qual a sobreposição de espaços e edifícios parece guardar uma memória viva e cumulativa do tempo, como se, como afirma Struth, ainda fosse possível ver na cidade os vestígios antigos dos seus mais ilustres habitantes. $\bigcirc$ espaço surge, assim, como o fiel depositário da memória, que a fotografia capta, e que obriga a uma leitura enquanto "processo mental".

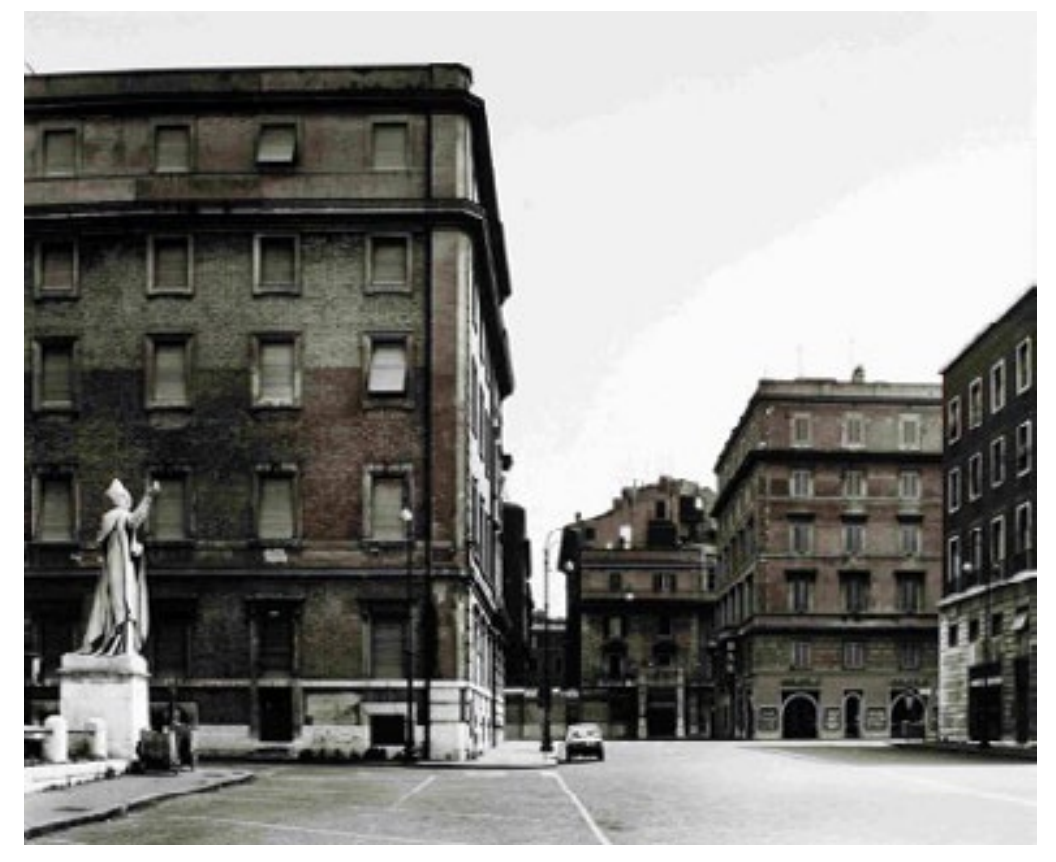

Fig. 10: Piazza Augusto Imperatore, Roma, 1984. Impressão em gelatina de prata. Dim: 66x84 cm.

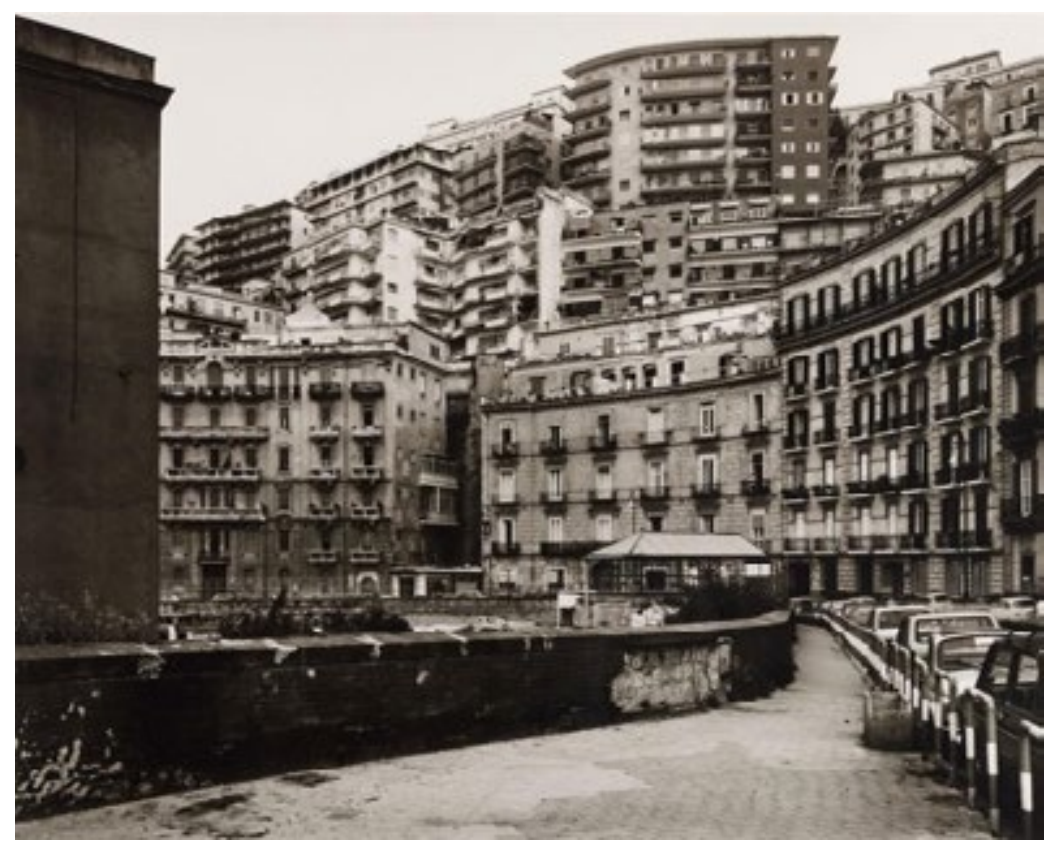

Fig. 11: Corso Vitorio Emanuele, Naples, 1989 Impressão em gelatina de prata. Dim: 45,5×56,7 cm.

O registo metafórico do espaço implica, simultaneamente, uma leitura dramatúrgica das próprias cidades, ou seja, a separação entre o espaço público 
e privado nas cidades ocidentais parece mimetizar o teatro, já que a vivência das pessoas se reparte entre a rua, que funciona como um "palco", onde desempenham os mais diversos papéis da vida de todos os dias, e a intimidade da casa, onde se recolhem no final da "representação", funcionando o lar como "camarim", onde os actores regressam à sua condição "ante-representacional". Poderá bem ser este o papel do fotógrafo, enquanto adivinho ou profeta, ou seja, o de revelar, na fotografia, as marcas dos acontecimentos da cidade, dos seus "crimes", que, embora invisíveis a olho nu, a imagem fotográfica revela a partir da sua inscrição no próprio espaço, como afirmou Benjamin, uma vez mais a partir da fotografia de Atget. (Fig. 12). A intensificação do foco sobre determinados edifícios, sobretudo no período inicial, em que utilizava maioritariamente o preto e branco (Fig. 13), parece confirmar a dimensão inteligível do seu trabalho, e o esforço necessário do espectador no sentido da leitura histórica do espaço.

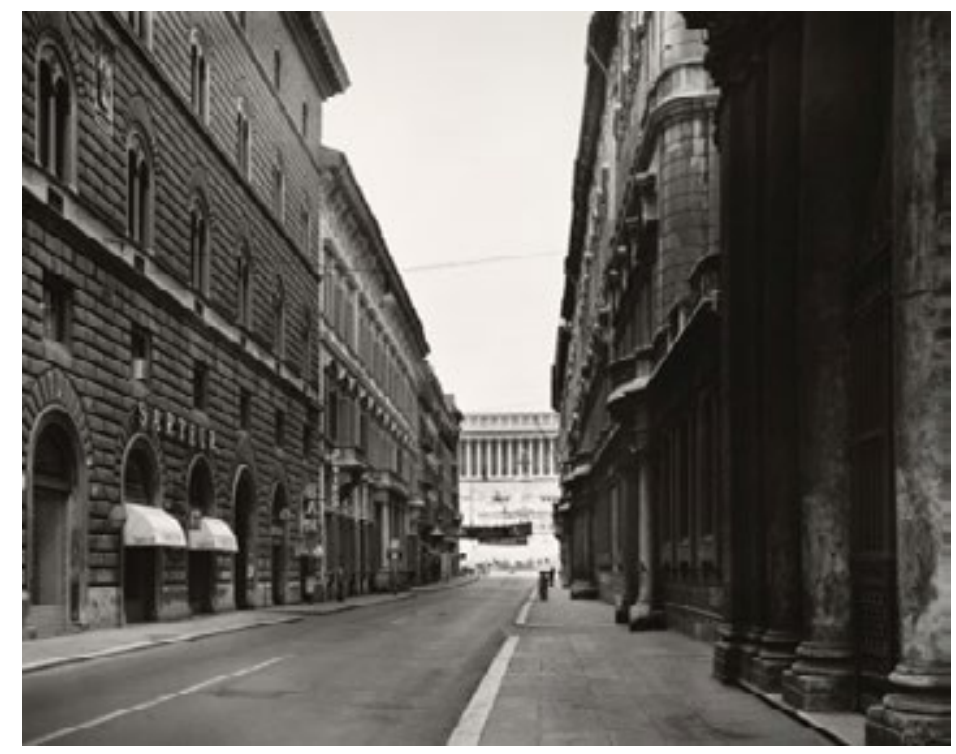

Fig. 12: Eugène Atget. Coin de la rue Valette et Panthéon, Paris, 1925. Impressão em albumina de prata. Dim: $18 \times 24 \mathrm{~cm}$.

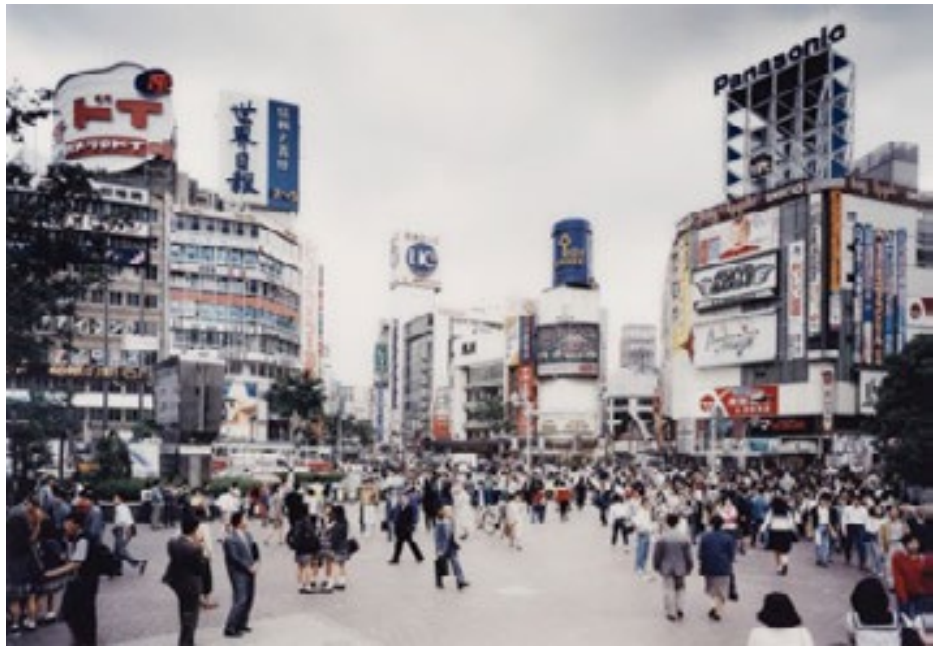

Fig. 13: Via del Corso, Roma, 1984. Impressão em gelatina de prata. Dim: $66 \times 84 \mathrm{~cm}$ 
Em contraste com as cidades ocidentais, Struth fotografa também as cidades orientais, constatando que, aí, a vida se passa essencialmente nas ruas, apinhadas de gente, nas quais as grandes imagens da publicidade invadem o espaço, invertendose o referido sentido dramatúrgico da própria história, em que "palco" e "camarim" parecem sobrepor-se, ou mesmo coincidir, elidindo-se, na ausência de ruas vazias, o sentimento ocidental de "presença" de quem recentemente aí apresentou um papel (Fig. 14). Esta constatação é testemunho de um sentido diverso da manifestação da história, espelhada no modo como as pessoas habitam as cidades no oriente, invertendo-se o conceito de "marcas do crime", inscritas no espaço das cidades do ocidente, que Struth invocava seu trabalho inicial, a partir das fotografias de Atget.

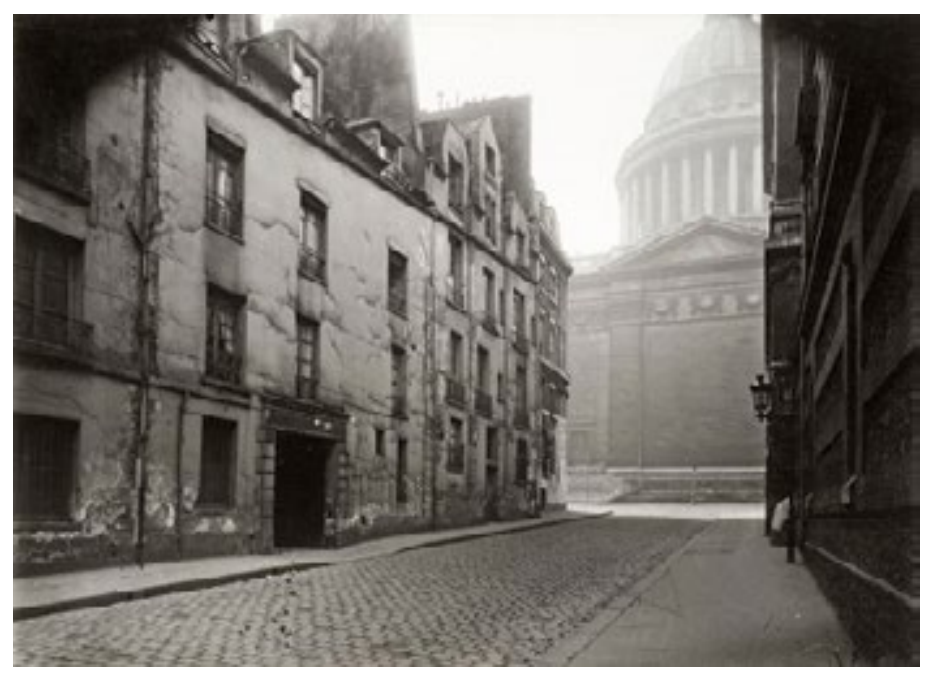

Fig. 14: Shibuya Crossing, Tokyo, 1991. Impressão cromogénica. Dim: 187,6×245,7 cm.

O retrato individual e familiar é um outro vector em que assenta a sua fotografia, pois, como afirma, a família é ainda a célula que molda a sociedade e, neste sentido, a própria história (Fig. 15 e Fig.16). Porém, e ao contrário da concepção clássica do retrato, Struth não procura captar a profundidade dos caracteres, já que a câmera é um factor que induz a pose, e, portanto, a representação de um papel, o que inviabiliza qualquer suposta "verdade absoluta" psicológica do retratado. O que procura é criar as condições para que as pessoas possam, no exacto momento do retrato, revelar uma presença autêntica, uma verdade que é válida apenas naquele tempo e lugar, o que vem a caracterizar também os seus inúmeros retratos individuais (Fig. 17).

O questionamento do estatuto das imagens ao longo do tempo constitui um outro tópico do seu trabalho, construído agora a partir de um conjunto de fotografias captadas em igrejas renascentistas e barrocas em Itália, particularmente em Veneza, nas quais, através da relação que o espectador estabelece com a imagem, Struth confirma que, a partir do século XVI, as imagens mantêm ainda uma função religiosa, mas não possuem já qualquer carácter sagrado.

A dessacralização das imagens, e a resposta física e psíquica do espectador perante elas, constitui o mote para as séries fotográficas de diversos museus do mundo (Louvre; Prado, Pergamon Museum; Instituto de Arte de Chicago, Kunsthistorisches Museum, entre outros), nas quais existe uma coreografia de gestos semelhantes entre 
as personagens das pinturas e os espectadores que as observam. Este jogo entre a imagem, que nos olha, e o olhar do espectador, e também a mimetização dos gestos das figuras dos quadros, reitera o questionamento acerca do acto de ver arte, assim como do próprio papel que a arte desempenha na vida histórica dos seres humanos e dos povos (Fig.18).

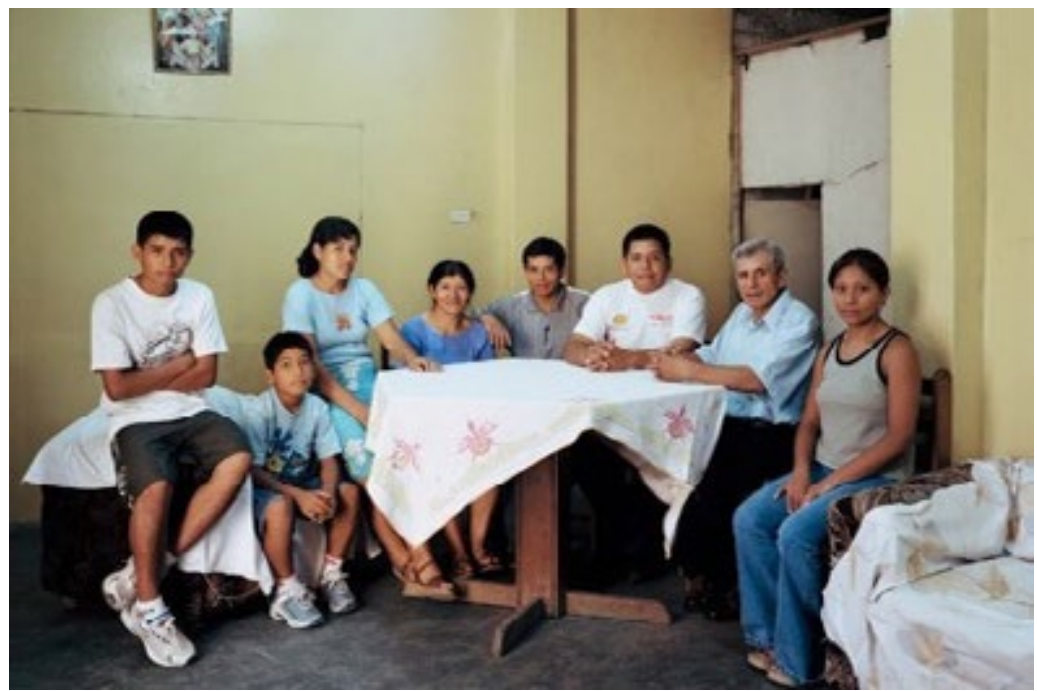

Fig. 15: The Ayvar Family Lima, 2005. Impressão cromogénica. Dim: 180x220 cm.

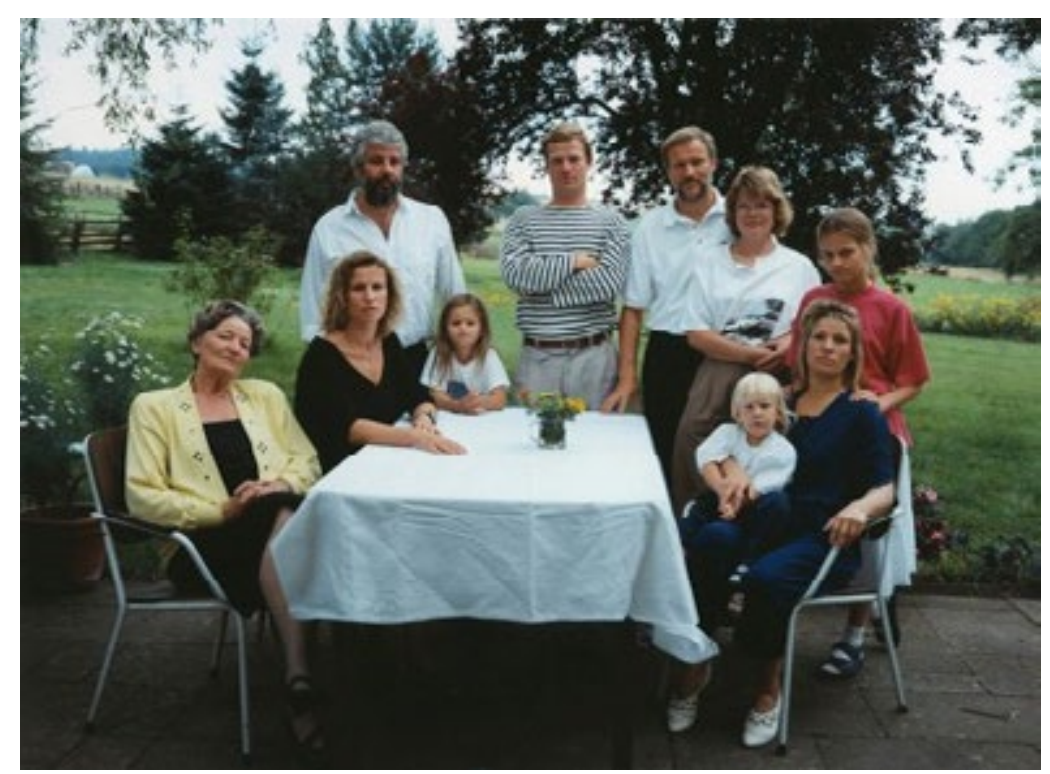

Fig. 16: The Bernstein Family. Mündersbach, 1990. Impressão cromogénica Dim: 125,8×158.

Para além das cidades, dos retratos, e dos museus, Struth realizou, na década de 1990, uma série de fotografias da exuberante natureza das florestas da China e da Austrália, entre outras, a que deu o título Paraíso (Figs. 19 e 20), nas quais o que avulta não é a paisagem de per si, mas o valor que podem ganhar enquanto metáfora da reconstrução da identidade; ou seja, Struth vê no final da guerra fria (finais da década de 1980) a possibilidade de reconstrução da identidade do mundo, identidade a que fotógrafo é particularmente sensível, já que, ao nascer no final da segunda guerra mundial, numa Alemanha devastada pelos aliados, se viu obrigado a uma redefinição 
da sua própria identidade enquanto alemão, no período pós-nazi. Para Struth, as imagens constituem-se o "texto" onde a história se revela, devendo ser lidas como um palimpsesto, onde os vários acontecimentos, cujas marcas mais ou menos ocultas no espaço e no tempo, se tornam legíveis através da fotografia.

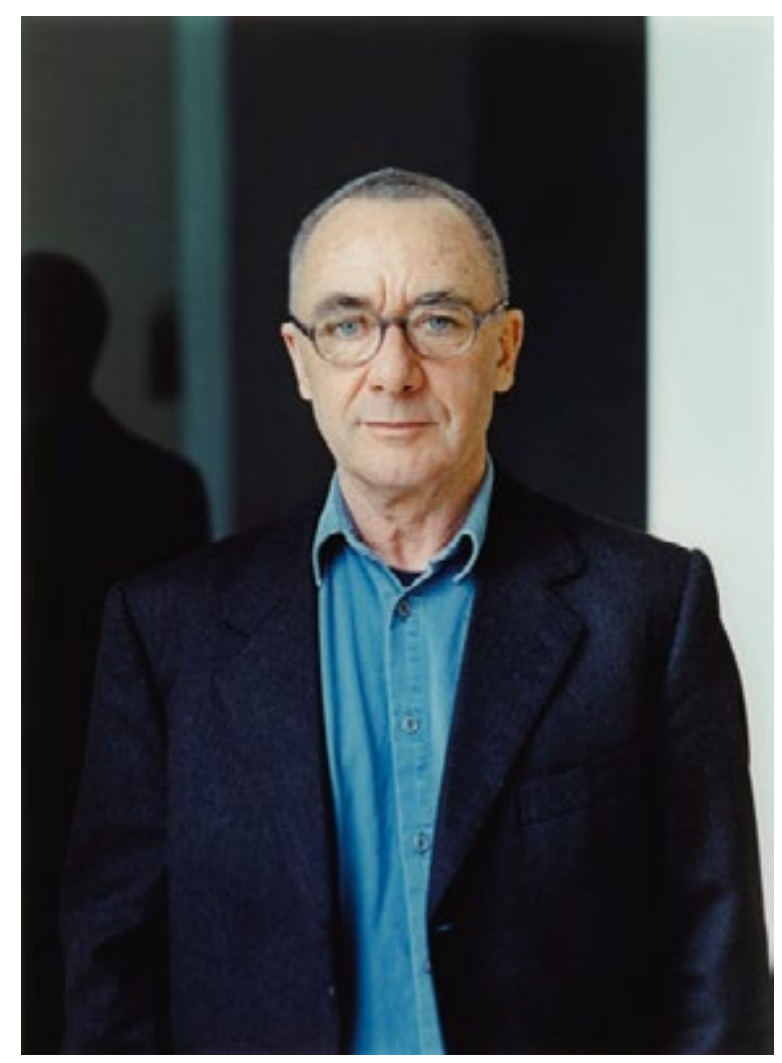

Fig. 17: G. Richter 1993. Impressão cromogénica. Dim: 80,3×58,4cm.

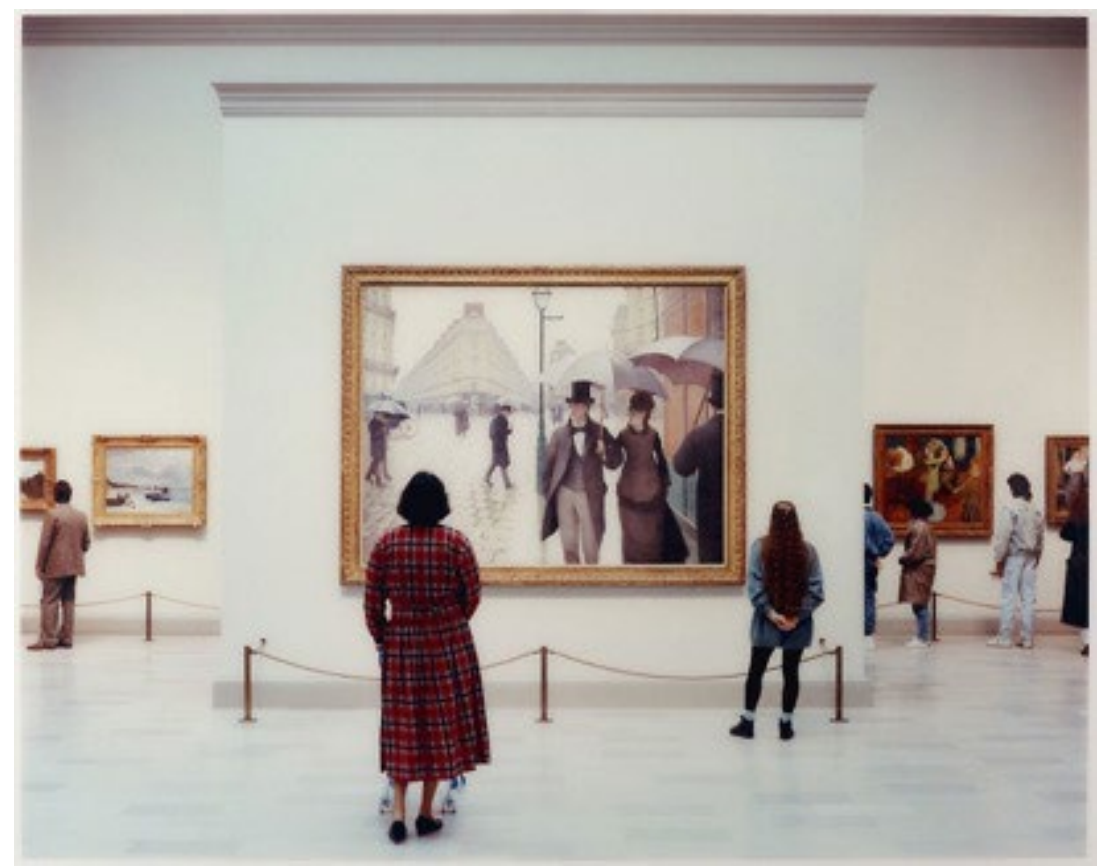

Fig. 18: Art Institute of Chicago 2. Chicago, 1990. Impressão cromogénica. Dim: 180x215 cm. 


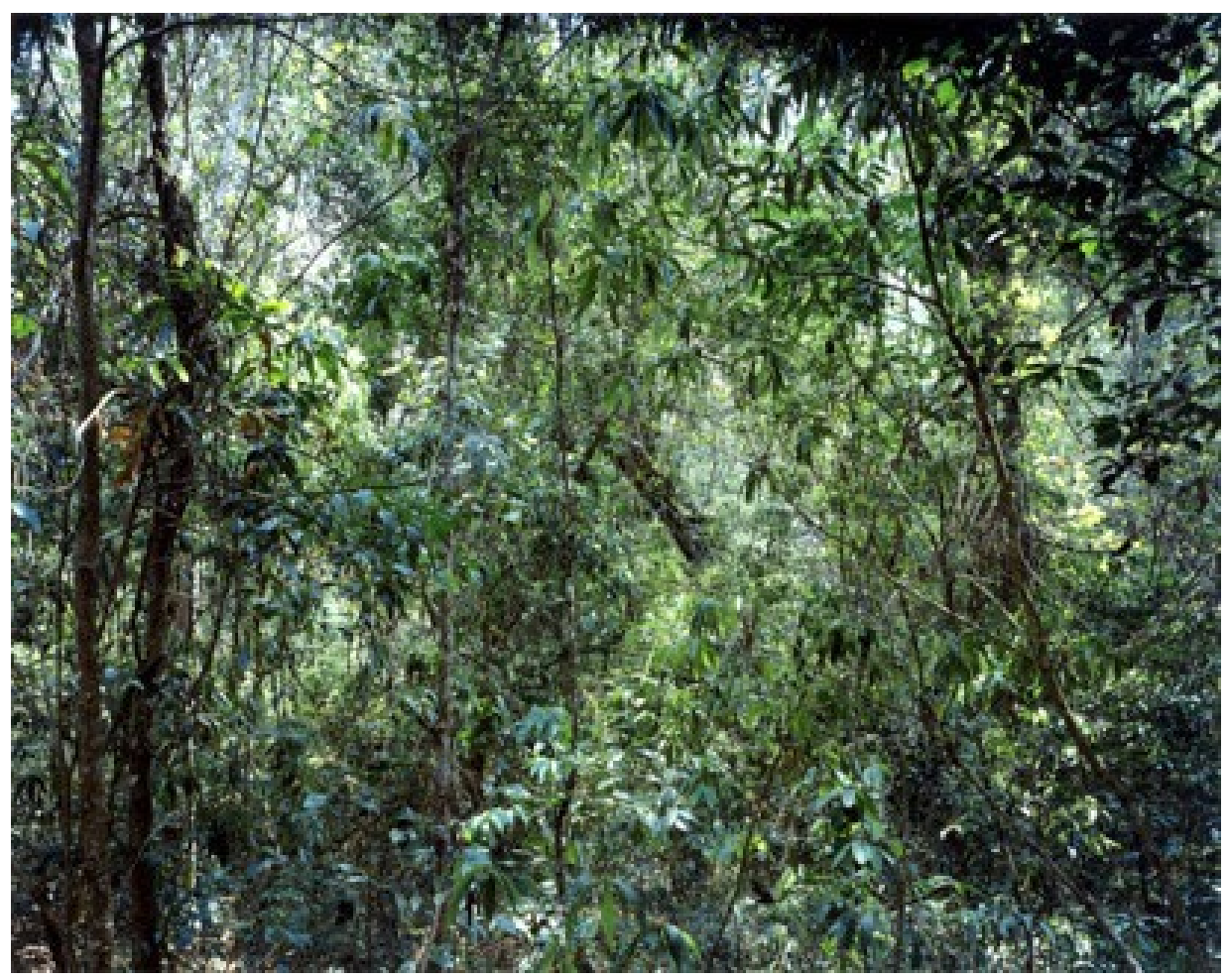

Fig. 19: Paradise 5. Daintree Australia, 1998. Impressão cromogénica. Dim: 172,1×209,9cm.

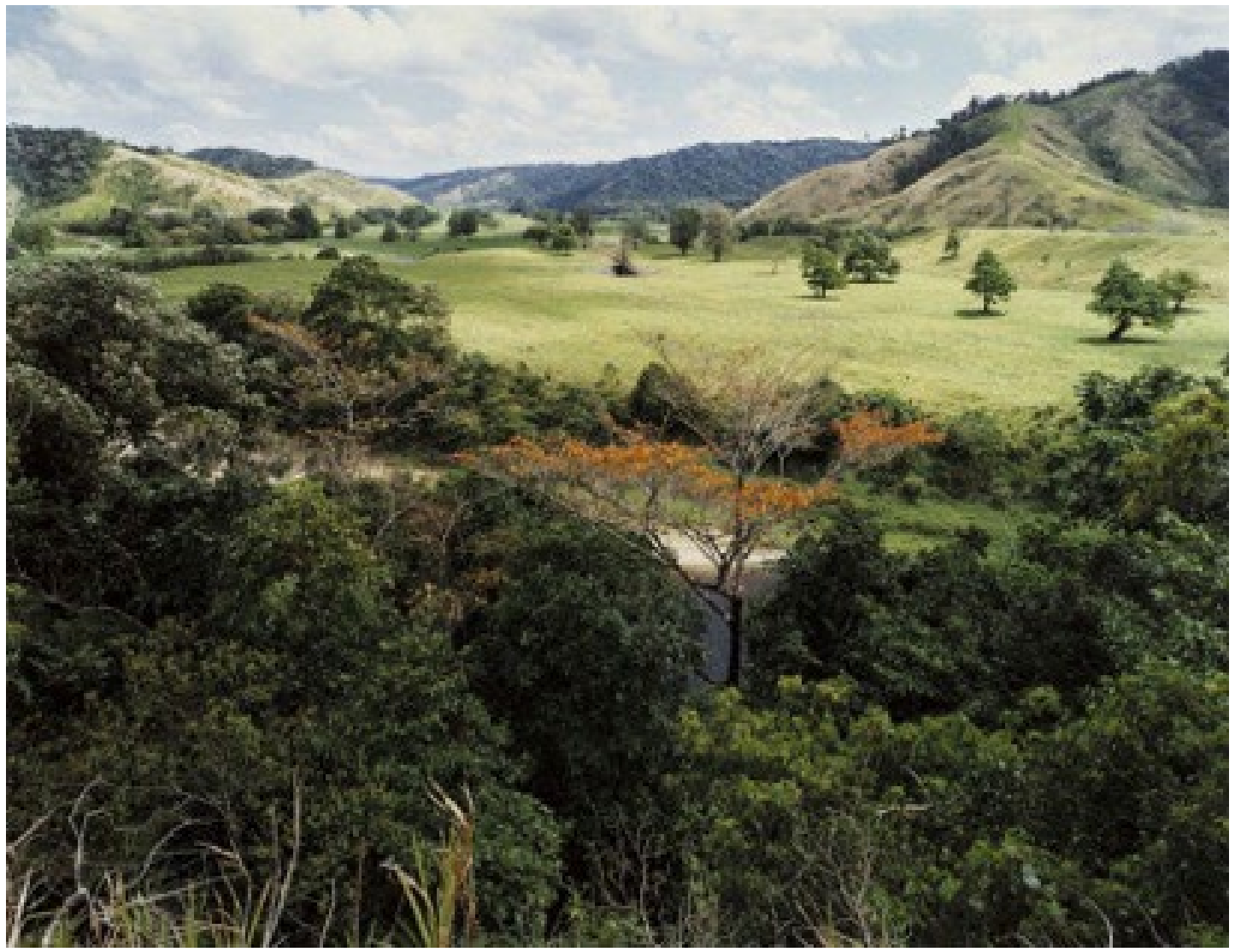

Fig. 20: Paradise 9, Xi shuang Banna, China, 1999. Impressão cromogénica. Dim: 269,4×339,4 cm. 


\section{Conclusão}

Na fotografia analógica, cada negativo é, afinal, único e original, e apenas a "positivação" desse mesmo negativo é que permite um conjunto de múltiplos, facto que, no limite, não deixa de colocar a verdadeira questão: o que é um original e um múltiplo em arte? Independentemente desta questão, que deu corpo à reflexão sobre a dimensão ontológica da fotografia, Jeff Wall procura uma autonomia para a fotografia que se baseia na sua relação com as artes plásticas, repensando as questões espaciais e compositivas, mas também com o cinema, seja pelo facto de trabalhar com actores profissionais, os quais assumem o duplo papel de modelos e de personagens, seja pelo facto de recuperar as dimensões narrativa e figurativa, considerando-as como elementos fundamentais de uma ontologia da imagem fotográfica. Ao mesmo tempo, complexifica o seu trabalho de um ponto de vista conceptual, ao trabalhar um conjunto de conceitos como o de verdade, a partir de Nietzsche, entre outros, o que the permite desenvolver a noção de grotesco como um dos denominadores do seu trabalho. Ao mesmo tempo, segundo Wall, é na representação da "gestualidade" como forma corpórea, que importa da pintura para a fotografia, que a própria consciência histórica se manifesta .

Por seu turno, Thomas Struth opera uma leitura dramatúrgica e metafórica do espaço por via da fotografia, procurando revelar através das imagens o movimento da história, ou seja, os acontecimentos que aparentemente o tempo vai ocultando, mas cujas marcas se encontram no espaço, cabendo esse trabalho de "arqueologia" ao fotógrafo, acabando o seu trabalho por exorbitar, no limite, uma dimensão exclusivamente documental. Na obra do fotógrafo alemão, a fotografia assume um papel decisivo na própria formação da auto-consciência dos indivíduos e dos povos, constituindo-se instrumento mediador para a leitura do mundo, sublinhando a necessidade de assumir a concepção, realização e recepção das imagens como um "processo mental".

\section{Referências}

BENJAMIN, Walter. A Modernidade (Pequena História da Fotografia). Lisboa, Assírio \& Alvim, 2006.

NIETZSCHE, Friedrich. O Nascimento da Tragédia (Acerca da Verdade e da Mentira no Sentido Extramoral). Relógio D’Água, Lisboa, 1997.

JEFF WALL. Catalogue Raisonné 1978-2004. Schaulager/ Steidl, Switzerland-Göttingen, 2005 (cat.).

WALL, Jeff. Gestus: Scritti sull’Arte e la Fotografia. Quodlibet, Macerata, 2003. 
WALL, Jeff. Ensayos y Entrevistas. Centro de Arte de Salamanca, Salamanca, 2003.

THOMAS STRUTH: Photographs 1978-2010, Museu de arte Contemporânea de Serralves, Porto, 2012 (cat.).

THOMAS STRUTH: Making Time, Museo Nacional del Prado, Madrid, 2007 (cat.).

THOMAS STRUTH: Still, Shirmer Art Books, Nîmes-Amsterdam-Paris, 2001 (cat.).

SANTOS, Diogo. O Grotesco, a Verdade e a Dimensão Dramatúrgica na Fotografia de Jeff Wall. Dissertação de Mestrado em Crítica, Curadoria e Teorias da Artes, Faculdade de Belas-Artes da Universidade de Lisboa, (policopiado).

\section{Videografia}

WILLIAM KLEIN. Provas de Contacto. Midas, 2009 (DVD). 